\title{
Degeneration of a bioprosthetic valve in mitral position ffter 21 years of implantation
}

\author{
Alaa Hijazi', Ferit Çiçekcioğlu', Ufuk Tütün1, Salih Fehmi Katırcıŏglu²
}

1) Bozok University Medical Faculty, Department of Cardiovascular Surgery, Yozgat, Turkey

2) Ankara Resarch Hospital Department of Cardiovascular Surgery, Ankara, Turkey

\section{Summary}

\begin{abstract}
Abstruct: Structural bioprosthetic valve degeneration is the most prominent drawback of these valves. The durability of bioprosthetic valve is less with mitral than aortic ones. Herein we present a case who had undergone a bioprosthetic mitral valve replacement 21 years ago when he was 31 years old. Echocardiography showed 3 degree mitral regurgitation with gradient 23/12 mmgh, systolic pulmonary artery pressure (SPAP) $48 \mathrm{mmgh}$, left atrium diameter was $8 \mathrm{~cm}$ and 3 degree tricuspid regurgitation. The bioprosthetic valve in mitral position was replaced with No.29 st Jude mechanical valve and Tricuspid valve Devege annuloplasty was performed. The postoperative period was uneventful.
\end{abstract}

Keywords: Bioprosthetic valve, mitral position, valve replacement.

\section{Case}

Herein we present a case who had undergone bioprosthetic mitral valve replacement 21 years ago when he was 31 years old. He came to our clinic complaining from shortness of breath on heavy exertion. Echocardiography demonstrated 1 to 2 degree mitral regurgitation with gradient $16 / 10 \mathrm{mmgh}$, systolic pulmonary artery pressure $40-45 \mathrm{mmgh}, 2$ degree tricuspid regurgitation and left atrium diameter was $7.5 \mathrm{~cm}$. Cardiac catheteriztion was performed and minimal mitral regurgitaion with systoic pulmonary artery pressure $60 \mathrm{mmgh}$ was observed. We followed up the patient medically for 6 months, then he came back to our clinic camplaining from shortness of breath on light effort. Echocardiography showed 3 degree mitral regurgitation with gradient 23/12 mmgh, SPAP $48 \mathrm{mmgh}$, left atrium diameter was $8 \mathrm{~cm}$ and 3 degree tricuspid regurgitation. Surgery was performed via re-median sternotomy and under mild hypothermic cardiopulmonary bypass. The bioprosthetic valve in mitral position was replaced with No. 29 st. jude mechanical valve and tricuspid valve Devege annuloplasty was performed. Gross examination of the explanted xenograft showed some degenartive changes of the cusps and the tissue was fragile (Figure.1). Pathologic studies revealed dystrophic calsifications and degenerative changes in the bioprosthetic valve. The postoperative period was uneventful. He was discharged on 
the fourth day postoperatively. We called the patient 15 days later for general control. He did not have any complaint. The echocardiographic studies revealed minimal mitral regurgitation and SPAP was $38 \mathrm{mmgh}$.

\section{Discussion}

Durability expectations for tissue valves range from 5 to 20 years. Durability can be extended by treatments that address calcification and designs that address mechanical wear. Tissue valves have become a practical option for elderly patients and for those who cannot tolerate the anticoagulation therapy required for mechanical valve recipients. Time-related dystrophic calsification is one of the major limitations to the durability of bioprosthetic valves. In the present patient, the prosthetic valve became hard and fragile as a result of calcification, and this resulted in degenerative destruction.

The destruction of an implanted bioprosthesis in the heart would most likely be due to dynamic mechanical stress as well as to an immunological response to the glutaraldehyde-treated bioprosthesis. ${ }^{(15)}$ As mentioned

\section{References}

1. Cohn LH: Atrioventricular valve replacement with a Hancock porcine xenograft. Ann Thorac Surg 1991; 51:683. discussion 684.

2. Borger MA, Armstrong S, et al: Twenty-year results of the Hancock II bioprosthesis. J Heart Valve Dis 2006; 15:49. Discussion 55.

3. Burdon TA, Miller DC, Oyer PE, et al: Durability of porcine valves at fifteen years in a representative North American patient population. J Thorac Cardiovasc Surg 1992; 103:238. discussion 251

4. Doorn CA, Stoodley KD, Saunders NR, et al: Mitral valve replacement with the Carpentier-Edwards standard bioprosthesis: Performance into the second decade. Eur J Cardiothorac Surg 1995; 9:253.

5. Bernal JM, Rabasa JM, Lopez R, et al: Durability of the Carpentier-Edwards porcine bioprosthesis: Role of age and valve position. Ann Thorac Surg 1995; 60:S248

6. Cohn LH, Collins JJ Jr., Rizzo RJ, et al: Twenty-year follow-up of the Hancock modified orifice porcine aortic valve. Ann Thorac Surg 1998; 66:S30

7. Marchand M, Aupart M, Norton R, et al: Twelve-year experience with Carpentier-Edwards PERIMOUNT pericardial valve in the mitral position: A multicenter study. J Heart Valve Dis 1998; 7:292.

8. Myken PS: Seventeen-year experience with the St Jude medical biocor porcine bioprosthesis. J Heart Valve Dis 2005; 14:486.

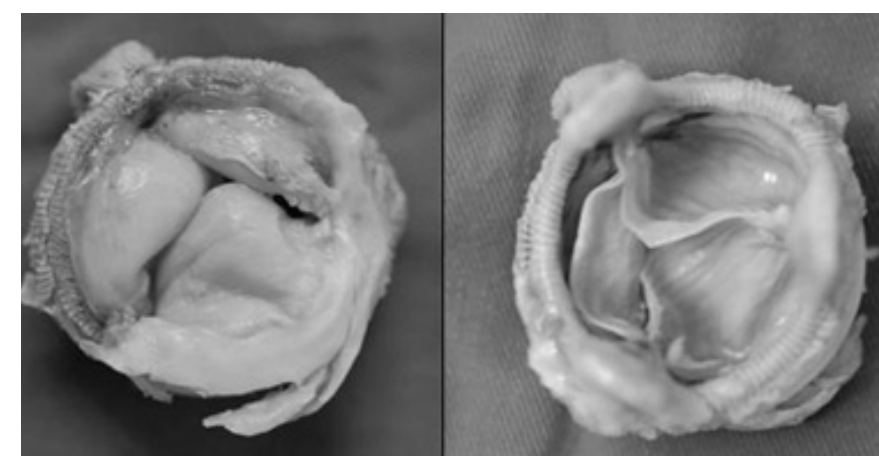

above, bioprosthetic valves dysfunction occurs more rapidly in the mitral than in the aortic position.

In the present case, the patient's medical record showed that dysfunctioning of the bioprosthesis in the mitral position was found 21 years after implantation; this period of bioprosthesis durability is unusually long for the mitral position and in a patient of this age. Mitral tissue valves have demonstrated susceptibility to calcification and wear due to the high systolic pressure placed on the closed leaflets. Here such calsification was observed after 21 years.

9. Poirer NC, Pelletier LC, Pellerin M, Carrier M: 15-year experience with the Carpentier-Edwards pericardial bioprosthesis. Ann Thorac Surg 1998; 66:S57.

10. Pupello DF, Bessone LN, Hiro SP, et al: Bioprosthetic valve longevity in the elderly: An 18-year longitudinal study. Ann Thorac Surg 1995; 60:S270; discussion S275

11. Zipes D, Braunwald E: A Textbook of Cardiovascular Medicine. Philadelphia, Saunders, 2004

12. Jamieson WR, Tyers GF, Janusz MT, et al: Age as a determinant for selection of porcine bioprostheses for cardiac valve replacement: Experience with Carpentier-Edwards standard bioprosthesis. Can J Cardiol $1991 ; 7: 181$

13. Jamieson E, Rosado LJ, Munro AI, et al. Carpentier-Edwards standard porcine bioprosthesis: primary tissue failure (structural valve deterioration) by age groups. Ann Thorac Surg. 1988;46:155-162.

14. David, TE, Armstrong, S, Sun Z. The Hancock II Bioprosthesis at 12 years. Ann Thorac Surg. 1998;66:S95-98.

15. Yasuhisa Shimazaki, Setsuo K, Fumihiro Takeda, Takao Watanabe, Kiyoshige Inui Mitral Valve Re-replacement for Impaired Bioprosthesis after 19 Years in a Patient Undergoing Steroid Treatment

Corresponding author: Dr. Alaa Hijazi

Mail: dralaahj@yahoo.com 